\title{
Critical connections: personal learning environments and information literacy
}

\author{
Alison Hicks* and Caroline Sinkinson \\ Department of Arts \& Humanities, University Libraries, University of Colorado, Boulder, \\ CO, USA
}

(Received 22 April 2013; final version received 30 October 2014)

\begin{abstract}
Personal learning environments (PLEs) and critical information literacies (CILs) are two concepts that have been presented as responses to the challenges of the rich and complex information landscape. While both approaches support learners' critical engagement with new information environments, each was developed within a different field. This paper connects and contrasts PLEs and CILs in order to explore the design of pedagogical responses to the information environment. Through a careful examination of PLE and CIL literature, the paper demonstrates that information literacy education intersects with the concepts and goals of PLEs. As such, the authors suggest that PLE scholarship informed by CIL scholarship, and vice versa, will yield a deeper understanding of modern learning contexts as well as a more holistic and responsive learner framework. The example of the research assignment will be used to demonstrate the viability of this approach. With these propositions, the authors invite educators, librarians and information technologists to engage in a dialogue about these concepts and the potential for pedagogical change.
\end{abstract}

Keywords: personal learning environments; information literacy; information landscape; self-directed learning

\section{Introduction}

Educational theorists have long been calling for new pedagogies that are responsive to changing digital information landscapes, that position learners in active and participatory roles and that afford authentic learning opportunities (Brown and Adler 2008; Jenkins 2009; McLoughlin and Lee 2008; Siemens 2005). These changes mark a significant shift in how scholars understand learning in higher education. The need for alternative educational solutions is amplified by the nature of developing information landscapes, which can be described as the intersubjectively created spaces that have resulted from human interaction, in which information is created and shared and eventually sediments as knowledge' (Lloyd 2010, p. 9). Advances in technology, which include lower barriers to participation, have greatly increased the amount of information available on the open web. This explosion in content is forcing educators to reshape their understanding of information, particularly in terms of traditional conceptions of knowledge, authority and validity. As an example, these changes can be seen in shifting practices of scholarship, or 'scholars' use of

*Corresponding author. Email: alison.hicks@colorado.edu 
participatory technologies and online social networks to share, reflect upon, critique, improve, validate, and further their scholarship' (Veletsianos and Kimmons 2012b, p. 768). This also means that educators must re-examine the capacities that learners need to engage in inquiry as well as the way that they meet these needs.

Personal learning environments (PLEs) and critical information literacies (CILs) are approaches to learning and inquiry that are responsive to these new information landscapes. Conceptualised as complexes of activities, tools and values, they were developed within different fields, that is, educational technology and information studies. Despite their similar underlying motivations and goals, they have never been compared nor contrasted, probably due to their origins in different areas of study. As such, the first aim of this paper is to explore PLE and CIL literature to demonstrate how an approach to inquiry that is grounded in PLE and CIL concepts is better equipped to meet learner demands in emerging information landscapes than previous models. Through this examination, the authors will highlight the similarities and differences between each approach as well as the ways in which the two concepts complement each other. This leads to the secondary goal of the paper, which is to contend that PLE scholarship informed by CIL scholarship, and vice versa, will position educators to respond holistically to modern learning environments. With these propositions, the authors invite educators, librarians and information technologists to engage in a dialogue about these concepts and the potential for pedagogical change.

Throughout the paper, the authors will use the concept of a research assignment to illustrate the need for alternative approaches to the teaching of inquiry. The research assignment is typically defined as a paper that 'evaluates sources of information, relates the accounts of information to one another, frames an argument that ties them together, and either reveals something important about the sources themselves or develops into a new contribution on the same topic' (Bizzell and Herzberg 1987, p. 303). While some educators have experimented with multi-modal versions of the research assignment, print- and text-based versions that are based around traditional academic information practices and norms remain the standard in North American undergraduate education. This means that it serves as an ideal way to explore learner needs, new information landscapes and the current teaching of inquiry in higher education. By redesigning an assignment around PLE and CIL concepts, the authors will illustrate how to model and engage students in a more holistic conception of inquiry within digital information landscapes.

This paper will start by providing a brief overview of historical approaches to learning and inquiry before further defining both PLEs and CILs. The paper will then explore how PLE and CIL approaches respond to modern learning environments through an examination of first, the information landscapes, and second, the approaches to learning within them. The paper will finish by exploring how PLE and CIL concepts could be used in the redesign of a research assignment.

\section{History and context}

The growing critique of learning management system (LMS) and information literacy (IL) standards demonstrates the shift from behaviourist to constructivist understandings of learning within the fields of educational technology and information studies. Defined as a technology solution to respond to and 'leverage' the Internet, the LMS, which is also known as a course management system (CMS) or virtual learning environment (VLE), was designed to manage online learning (Mott and 
Wiley 2013, p. 4). Comparably, the Association of College and Research Libraries (ACRL) Information Literacy Standards for Higher Education (2000), which define IL as the ability to identify an information need, and to locate, evaluate and use information, were developed in order to structure learner engagement in complex information landscapes.

Both of these solutions were early attempts to meet changing educational paradigms and information realities, but are now seen to fall short of enabling transformative learner experiences. In terms of the LMS, educators commonly criticise the closed and hierarchical structure that privileges an institutionally managed and teacher-driven approach to learning (Dalsgaard 2006; Johnson et al. 2006; Littlejohn 2011; Mott 2010; Mott and Wiley 2013). In the case of the IL Standards, educators censure the way that the standards reduce information seeking and interaction to linear and simplistic steps without acknowledging the learner's active role in diverse contexts within the knowledge economy (Coonan 2011; Elmborg 2006; Jacobs 2008; Kapitzke 2003; Luke and Kapitzke 1999; Swanson 2005; Tuominen, Savolainen, and Talja 2005). Accordingly, both the LMS and the IL Standards are increasingly seen as being in conflict with the learner-centred, active and reflective approaches to learning that are necessary for complex digital information landscapes.

These criticisms can be seen more concretely through an examination of how inquiry is taught, and more specifically the research paper assignment. Teaching research and inquiry has always been especially important within higher education, but traditional methods, which tend to centre around text-based realities and traditional modes of scholarly discourse, no longer match information practices. More specifically, the rigid and procedural nature of the traditional research assignment is seen to distance students from inquiry. Furthermore, its inability to engage students authentically in conversation with other thinkers and writers means students fail to understand their own voice in inquiry, or see inquiry as a conversation they can enter, whether they are in civic, social or scholarly contexts (Detmering and Johnson, 2012; Fister, 1993; Leckie, 1996; Lee 2013; Nelson 1994). In this way, and like the LMS and the IL Standards, the traditional research assignment is seen as increasingly anachronistic in these new information landscapes.

\section{Definitions}

An examination of the historical context shows that PLEs and CILs grew out of educational technologists' and librarians' increasing dissatisfaction with the ability of the LMS and IL standards to meet both learning and learner needs. This section will define each of these concepts.

\section{Personal learning environment}

While there are numerous competing definitions and conceptions of PLEs, the authors align with Attwell's (2010) definition, which summarises the essential characteristics:

PLEs are made-up of a collection of loosely coupled tools, including Web 2.0 technologies, used for working, learning, reflection and collaboration with others. PLEs can be seen as the spaces in which people interact and communicate and whose ultimate result is learning and the development of collective know-how. A PLE can use social 


\section{A. Hicks and C. Sinkinson}

software for informal learning which is learner driven, problem-based and motivated by interest - not as a process triggered by a single learning provider, but as a continuing activity.

PLEs are spaces for the modern learner to create, explore and communicate (Dalsgaard 2006, p. 2). While they include and respond to new technology tools, PLEs are characterised as an approach to learning rather than a set of applications (ELI 2009, p. 1).

\section{Critical information literacy}

CIL is a complex set of behaviours, attitudes and interactions that a learner adopts to engage critically in information landscapes. It is founded in critical pedagogy and critical information studies and reframes IL as a culturally and socially situated phenomenon (Luke and Kapitzke 1999, p. 5). The CIL approach to inquiry encourages an individual who is not passive, but one who poses questions and interrogates information systems; who explores, plays, internalises and contributes; one who reflects and revises information practices and beliefs (Accardi, Drabinski, and Kumbier 2010, p. xii).

\section{Information landscapes}

The paper will now turn to explore the changing context of modern learning environments, starting with an examination of information landscapes, which are characterised as open, broad and participatory. This section will explore how PLE and CIL approaches respond to these emerging contexts in a highly complementary manner.

\section{Openness}

Openness, defined as 'both a technical feature and what might be called a 'state of mind", is a central characteristic of information landscapes (Weller 2011). Open and free software, which allows anyone to create, edit and disseminate shared content, is an example of openness. However, the culture of openness found in modern information landscapes extends beyond these technical affordances to assume that by default, information should be freely accessible by all (Stewart 2013).

This culture of openness has had a significant impact on the educational sphere, as shown by the rise of open educational resources (OER) and open access (OA). While a complete transition to information openness has not yet been realised, educational practices that are entirely focused around traditional, closed and proprietary knowledge systems are in tension with these changing information landscapes. In contrast, PLE and CIL approaches match the values underpinning the culture of openness. The PLEs, for example, are structured to engage the learner with information from the wider community, rather than just information that is sanctioned by the teacher or institution (ELI 2009). In this way, the learner engages with information that is liberally licensed for re-use ... free from restrictions to modify, combine and re-purpose' (Schaffert and Hilzensauer 2008, p. 6). Furthermore, the learner is invited to engage in content creation, thereby mirroring the values of open culture. Likewise, the underlying values of CIL approaches encourage the learner 
to question customs of knowledge production, including "what should count as knowledge,' 'for whom' and 'in whose interests" (Luke and Kapitzke 1999, p. 484). By questioning the traditional hierarchical systems 'wherein expert authorities determine what counts as "knowledge", learners are positioned to engage in decentralised and open information exchange (Pawley 2003, p. 426).

Source requirements in the traditional research assignment illustrate the tension between inherited educational practices and the open values of modern information landscapes. For example, assignment guidelines frequently direct students to use local subscription-based library resources in lieu of open web or non-library sources (Holliday and Rogers 2013, p. 264). This is problematic because it suggests that sources of knowledge found on a library shelf are 'hard and fast truth' (Fister 1990, p. 506). It simultaneously devalues open content and new systems of dissemination and means that learners are not encouraged to question authority, significance and validity. The focus on subscription library resources that are not available after graduation further complicates the transferability of research skills.

\section{Broad}

Modern information landscapes can also be characterised by a rich tapestry of elements that include 'tools, artefacts, processes and physical connections' (Couros 2010 , p. 125). With the wider availability of free and open communication tools, the processes and networks involved in knowledge creation are made transparent, thereby adding more depth and breadth to information landscapes. In this way, information landscapes cannot solely be described as comprising formal or textual information products but must also include the connections and relationships therein.

Within academia, scholars' use of new tools and technologies has made the scholarly research process more visible. Scholars increasingly conduct dialogue through social media and blogs, for example, or exchange information through social bookmarking or tagging (Veletsianos and Kimmons 2012a). This content and conversation contribute to the broadening of information landscapes. Unlike traditional methods for teaching inquiry, PLE and CIL approaches accommodate the dynamic nature of these new scholarly processes. PLEs, for example, help learners to build, manage and adjust networks as they navigate through information landscapes (Chatti, Jarke and Specht 2010, p. 80). This includes understanding what Littlejohn (2011) refers to as the 'cumulative actions of others' such as recommendations and tag clouds as well as the relationships that form between people, teams, organisations and communities. Similarly, CIL approaches do not privilege the textual; instead they acknowledge the role of social, procedural and physical information within information landscapes (Lloyd 2007). As Talja (1997) points out, knowledge consists of 'a mix of scientific or expert knowledge, and unconscious, selective or culture-specific background assumptions' (p. 73). It is legitimised by communities of practice, which may see these assumptions as valid in some contexts, while questionable in others. In this way, CIL shifts the focus from information seeking and consumption to 'a way of knowing the many environments that constitute an individual's being in the world' (Lloyd 2007).

Traditional research assignments fail to capture these broad and lived experiences of inquiry within modern information landscapes. Learners are rewarded for their final essay, with little attention given to the intermediary research processes (Nelson 1990, p. 365). At the same time, success is commonly judged by the inclusion 
of formal textual or codified knowledge in the works cited page, rather than authentic dialogue with information sources and scholars.

\section{Participation}

The proliferation of freely available content creation and sharing tools means that modern information landscapes can also be distinguished by contributions from a broad base of participants. Low barriers to authoring and sharing enable participants to engage in dialogue with other thinkers and writers, as well as to experiment with personal creations (Jenkins 2009). If individuals engage as active participants instead of passive consumers they are able to circumvent traditional models of editorial control, thereby increasing the flow of information.

Within higher education, low barriers to participation broaden contributions to scholarly discourse by giving voice to a range of individuals, whether they are acclaimed senior faculty or novice undergraduates. This can be seen in the rise of alternative publication venues such as blogs or micro publishing sites as well as in the rise of new avenues for scholarly contributions such as curation and content sharing (Veletsianos and Kimmons 2012a). PLE and CIL approaches invite participation by encouraging learners to recognise the social and networked elements of inquiry and scholarship. Within PLEs, tools enable a learner to build a network of people and content, and establish new modes of communication (Chatti, Jarke, and Specht 2010). At the same time, by learning to be part of someone else's network, for example, by editing, organising and sharing content, learners come to appreciate the social components of their community and interactions, as well as starting to understand their own agency in this setting (Fisch 2007). Similarly, principles of CIL emphasise that inquiry is a process built on participation and the meeting of various voices in dialogue, rather than the passive consumption of sources (Jacobs 2008, p. 259). In this way, a CIL approach encourages the learner to recognise the role of context and social interactions as much as information sources in the development of new knowledge and meaning making.

\section{Learning approaches}

The growing complexities of information landscapes demand new approaches to learning that are learner-centred and self-regulated. This section will explore how PLE and CIL approaches to learning complement each other as they match the needs of modern information landscapes. While this section focuses on the individual learner's process, the authors recognise that the information landscape is networked and connected and that learning occurs neither in isolation nor in an entirely internal state (Siemens 2005).

\section{Learner-centred}

In an information landscape that is marked by broad participation, a learner's contributions and expressions are tied to his/her prior knowledge as well as to his/her new experiences (Swanson 2004, p. 261). In addition, changing modes and methods of expression mean that the learner has to take responsibility to decide which tools to use and what contributions and connections to make on an on-going basis. This means that static, imposed frameworks designed to manage inquiry and 
information are no longer viable solutions. Instead, a model of learning that is learner-centred will need to be adaptable, flexible and more personally meaningful in the face of changing landscapes.

Within PLEs, a learner gains control as he/she makes individual choices about the technologies he/she uses in alignment with his/her personal needs, style of learning, preferences, context or changing interests (Attwell 2007, p. 3; Downes 2012, p. 27; Johnson and Liber 2008, p. 8; Weller 2000, p. 183). By engaging with components of his/her PLEs, the learner participates and engages in 'purposeful tinkerings that often form the basis of situated understanding' (Brown and Adler 2008, p. 30). In this way, a learner constructs and manages an individually designed and self-reflective learning environment rather than one that is modelled around the teacher or institution.

The underlying values of CIL emphasise that meaningful knowledge construction occurs when a learner is encouraged to draw from prior information experiences and to reform them in light of new and emerging contexts (Swanson 2004, p. 265). The learner is not generic nor is the learning. This means that educators cannot establish an exemplar that directs all lines of inquiry and by which all learners' habits may be measured (Elmborg 2006, p. 196). The establishment of norms such as these also run the risk of disregarding 'variables of gender, class, religion, culture and ethnicity' and privileging learners who match 'those socially preselected for academic success' (Elmborg 2006, p. 194; Kapitzke 2003, p. 58).

The traditional research assignment is often driven by standards that favour imposed or institutional values over learner values and beliefs. The evaluation of information sources provides a good example. Imposed or transmitted value rubrics that are checklists for establishing the validity and credibility of an information source distance students from their interaction with information even though 'the only judge of 'aboutness' is the person who seeks to be informed 'about' something' (Elmborg 2012 , p. 84). This may also contribute to a student's tendency to remain passive, with little ownership in the inquiry process (Coonan 2011, p. 18).

\section{Self-regulated learner}

Within new information landscapes, learners are continually challenged to manage their own learning. The speed of change, as well as the growth of contextual information needs, means that learners are required to regulate the direction and scope of their learning throughout their lives (Buchem, Attwell, and Torres 2011, p. 11). This includes reflecting on strategies and practices that are effective as well as being able to identify gaps and needs for learning.

PLEs enable a learner to pool all of his/her learning experiences, whether these are workplace, academic or civic experiences. This brings 'together sources and contexts for learning hitherto separate' to form a comprehensive record that he/she may use to find patterns, connections or contradictions in his/her learning experiences (Attwell 2007, p. 7). In turn, this can be employed to make more informed and selfdirected decisions about learning needs.

Similarly, a CIL approach to learning encourages students to adopt a selfreflective stance that examines one's creation, dissemination and use of information (Swanson 2004, p. 264; Ward 2006, p. 396). In doing so, learners are encouraged to take the time to explore and adjust information strategies and practices as they learn more about their world. This reflection means that learners develop the capacity to 
identify the questions that are meaningful to them as well as being able to understand their orientation and trajectory within information landscapes (Elmborg 2006, p. 193).

Reflection is seldom a component of traditional research assignments. The completion of the assignment marks the end of the learner's engagement with the topic of inquiry as well as with their own process of investigation. The learner is not afforded the space to reflect, which inhibits the adaptation and revision of strategies for future acts of inquiry (Ward 2006, p. 398).

\section{Research assignment}

The previous sections have explored how approaches to learning that are based on concepts of PLEs and CILs may be more suited to meet learner needs in modern information landscapes. This section looks at how the research assignment can be used and adapted to provide a more meaningful approach to the teaching of inquiry.

Research assignments feature prominently in the undergraduate curriculum. Educators may use the research assignment to firstly, assess students' skills of inquiry and writing and secondly, to acculturate students into academic discourse and disciplinary content. In this way, these assignments are often miniature replications of the formal scholarly activity that academics enact throughout their professional careers (Elmborg 2006, p. 196). Despite being designed to model expert habits for the research novice, students often exhibit only superficial interaction with the process and the content of study (Fister 1993; Leckie 1996; Lee 2013; Nelson 1994). They may consequently experience research as a decontextualised, procedural task rather than engaging their own questions, knowledge or interests.

Components of the research assignment may also exist in tension with modern information landscapes, as discussed above. This includes the privileging of specific information sources, an emphasis on research product rather than research process and the imposition of an inauthentic audience. Traditional methods of teaching the research assignment may also conflict with the approaches to learning that are necessary in modern information landscapes. This includes the reliance on artificial evaluation mechanisms, the isolation of inquiry within the academic context, and the failure to recognise the importance of reflection. Educators are challenged to adjust the research assignment in order to avoid these potential pitfalls in the teaching of inquiry.

\section{Redesigning the research assignment}

PLE and CIL approaches to learning could be used to redesign the research assignment and frame inquiry as a process that is social and connected as well as tolerant of new and emerging modes of communication. Due to the participatory and open characteristics of both approaches, students are positioned to enter into conversation with a specific community or context while also remaining poised to scrutinise the specific information landscapes.

The nature of modern information landscapes means that the teaching and learning of inquiry should acknowledge the social and connected nature of knowledge construction. PLE and CIL approaches meet this need by revealing the social connections that lead to new knowledge and understanding. Within the academic context, this is exemplified through the academic's reliance on personal contacts and citation trails during their inquiry process (Leckie 1996, p. 202). The social and 
communicative aspects of this experience are less obvious to learners who are new to the process. By breaking down and unveiling the human interaction and dialogue in the process, students may more readily draw connections between these interactions and formal publications. In a redesigned assignment, this could involve asking students to identify aspects of informal scholarship, such as experts, key journals or conferences in the field in order to help them see patterns within the various streams of information and understand the collaborative nature of research (Sinkinson and Hicks 2013). This integrates students more widely into the discipline and the research process because the student learns to participate with the authentic audience beyond the classroom.

The breadth of information sources within modern information landscapes further demand a shift in the approach to teaching and learning. Approaches to inquiry based on PLEs and CILs are expansive enough to incorporate multiple modalities and forms of information, as well as diverse and chaotic information interactions. For example, a PLE approach supports the 'entire set of resources that a learner uses to answer questions, provide context, and illustrate processes' (ELI 2009, p. 1). A CIL approach helps to underscore this process-oriented understanding of inquiry. A result of these approaches would be an assignment in which students are free to pull from a variety of modalities and formats, including dominant and emerging sources of information. Rather than promoting one modality over another, students will use the information that is the most appropriate and useful for their specific questions. In this way, the students may develop a critical stance and learn to engage in contextual evaluation of sources, rather than merely subscribing to prescribed values.

Learners will pursue inquiry within digital information landscapes throughout their lives (Jacobs 2008). Despite this fact, current research assignments do not stress the real-world application of inquiry. Approaches to learning based on PLEs and CILs allow students to contextualise inquiry within a specific knowledge community. In PLEs, for example, a learner can start using the tools and the resources that are used in the practice of a field. In this way, PLEs can be seen as 'a tool intended to immerse yourself into the workings of a community' (Downes 2010). CIL approaches extend this idea by encouraging students to recognise and consequently shape the wider conventions and characteristics of the discipline or community, rather than remaining an onlooker. Within an assignment, learners might be asked to engage a specialist, either by commenting on a blog or through an interview. By viewing inquiry as entering a conversation, students learn not only how to 'research and write like the specialists who inhabit these communities' but also to 'participate in a world of already articulated ideas' (Elmborg 2003, p. 73).

These examples demonstrate the highly complementary nature of PLE and CIL approaches to learning. At the same time, CILs bring a unique critical lens to the teaching of inquiry that is not currently emphasised in PLE literature. The need for critical scrutiny is linked to broader questions about the role of technology in society as well as, more specifically, the fact that modes of communication are constantly changing and unpredictable (Hall 2011). For that reason, it is important that learners adopt a critical stance to information and technology in order to expose underlying values, dynamics and relationships of power. As such, while individually both the PLEs and CILs form useful approaches to inquiry, together they would offer a new approach to guide learner inquiry. More explicitly, the PLEs provide a practical structure for managing inquiry within modern information landscapes. A CIL approach, on the contrary, encourages the development of learners' critical dispositions towards 
and within information landscapes. Accordingly research assignments founded on PLEs and CILs encourage learners to examine entire systems of information from production through to distribution and dissemination.

\section{Conclusion}

In conclusion, this paper explores two approaches to learning that are responsive to changing information landscapes; PLEs and CILs. As McLoughlin and Lee (2008) note, the challenge for the new information environment is 'to facilitate learning, be less prescriptive, and be open to new media, tools, and strategies, while nurturing the skills of information evaluation as well as the blending and remixing, and recombination of ideas to reach creative solutions' (p. 20). This paper demonstrates that the interlocking of PLE and CIL approaches will offer strategies to help educators be more responsive in these ways.

While this paper focuses on a theoretical exploration, it is clear that a practical implementation of these ideas warrants more dialogue. In order to enact the ideas outlined here, a teacher will need to work as a facilitator, motivator, co-learner or coach rather than an authoritative figure at the front of the classroom. Students will need to work with self-direction and autonomy, which requires that they come to value informal, adaptive and flexible learning. These changing roles mark a significant transition from traditional learning and present questions such as:

- What capacities and practices will learners and teachers need to develop?

- How will the learner and teacher role be defined within these approaches?

- What barriers will inhibit the exploration of these approaches?

- What components of the traditional approach should be protected and maintained?

Working collaboratively, librarians and educational technologists can begin to address these questions as they design more meaningful and creative learning opportunities.

\section{References}

Accardi, M., Drabinski, E. \& Kumbier, A. (2010) Critical Library Instruction: Theories and Methods, Library Juice Press, Duluth, MN.

Association of College and Research Libraries (ACRL). (2000) 'Information literacy competency standards for higher education', [online] Available at: http://www.ala.org/ acrl/standards/informationliteracycompetency

Attwell, G. (2007) 'Personal learning environments - the future of elearning?', Lifelong Learning, vol. 2, pp. 1-8.

Attwell, G. (2010) 'Personal learning environments and Vygotsky', [online] Available at: http:// www.pontydysgu.org/2010/04/personal-learning-environments-and-vygotsky

Bizzell, P. \& Herzberg, B. (1987) 'Research as a social act', The Clearing House, vol. 60, no. 7, pp. 303-306.

Brown, J. S. \& Adler, R. (2008) 'Minds on fire: open education, the long tail, and learning 2.0', EDUCAUSE Review, vol. 43, no. 1, pp. 16-32.

Buchem, I., Attwell, G. \& Torres, R. (2011) 'Understanding personal learning environments: literature review and synthesis through the Activity Theory lens', Learning, vol. 54, no. 2, pp. 1-33. 
Chatti, M. A., Jarke, M. \& Specht, M. (2010) 'The 3P learning model', Journal of Educational Technology \& Society, vol. 13, no. 4, pp. 74-85.

Coonan, E. (2011) 'A new curriculum for information literacy: theoretical background', [online] Available at: http://arcadiaproject.lib.cam.ac.uk/docs/theory.pdf

Couros, A. (2010) 'Developing personal learning networks for open and social learning', in Emerging Technologies in Distance Education, ed. G. Veletsianos, Athabasca University Press, Athabasca, pp. 109-128.

Dalsgaard, C. (2006) 'Social software: e-learning beyond learning management systems', European Journal of Open, Distance, and E-Learning, [online] Available at: http://www. eurodl.org/materials/contrib/2006/Christian_Dalsgaard.htm

Detmering, R. \& Johnson, A. M. (2012) 'Research Papers Have Always Seemed Very Daunting: Information Literacy Narratives and the Student Research Experience', Portal: Libraries and the Academy, vol. 12, no. 1, pp. 5-22.

Downes, S. (2010) 'Pedagogical foundations for personal learning', [online] Available at: http:// www.slideshare.net/Downes/pedagogical-foundations-for-personal-learning

Downes, S. (2012) Connectivism and Connective Knowledge, [online] Available at: http://www. downes.ca/files/books/Connective_Knowledge-19May2012.pdf

Educause Learning Initiative (ELI). (2009) 'Seven things you should know about personal learning environments', [online] Available at: http://net.educause.edu/ir/library/pdf/ELI7049. pdf

Elmborg, J. (2003) 'Information literacy and writing across the curriculum: sharing the vision', Reference Services Review, vol. 31, no. 1, pp. 68-80.

Elmborg, J. (2006) 'Critical information literacy: implications for instructional practice', The Journal of Academic Librarianship, vol. 32, no. 2, pp. 192-199.

Elmborg, J. (2012) 'Critical information literacy: definitions and challenges', in Transforming Information Literacy Programs: Intersecting Frontiers of Self, Library Culture, and Campus Community, eds. C.W. Wilkinson \& C. Bruch, ACRL, Chicago, IL, pp. 75-95.

Fisch, K. (2007) 'Creating personal learning networks', [online] Available at: http:// thefischbowl.blogspot.com/2007/08/creating-personal-learning-networks.html

Fister, B. (1990) 'Teaching research as a social act: collaborative learning and the library', Reference Quarterly, vol. 29, pp. 505-509.

Fister, B. (1993) 'Teaching the rhetorical dimensions of research', Research Strategies, vol. 11, pp. 211-219.

Hall, R. (2011) 'Revealing the transformatory moment of learning technology: the place of critical social theory', Research in Learning Technology, vol. 19, no. 3, pp. 273-284.

Holliday, W. \& Rogers, J. (2013) 'Talking about information literacy: the mediating role of discourse in a college writing classroom', Portal: Libraries and the Academy, vol. 13, no. 3, pp. $257-271$.

Jacobs, H. L. (2008) 'Information literacy and reflective pedagogical praxis', The Journal of Academic Librarianship, vol. 34, no. 3, pp. 256-262.

Jenkins, H. (2009) Confronting the Challenges of Participatory Culture: Media Education for the 21st Century, MIT Press, Cambridge, MA.

Johnson, M., et al., (2006) 'Towards a reference model for the personal learning environment', Who's Learning? Whose Technology? Proceedings of the 23rd Annual Conference of the Australasian Society for Computers in Learning in Tertiary Education, Sydney University Press, Sydney, [online] Available at: http://www.ascilite.org.au/conferences/sydney06/proceeding/ pdf_papers/p141.pdf

Johnson, M. \& Liber, O. (2008) 'The personal learning environment and the human condition: from theory to teaching practice', Interactive Learning Environments, vol. 16, no. 1, pp. 3-15.

Kapitzke, C. (2003) 'Information literacy: a review and poststructural critique', Australian Journal of Language and Literacy, vol. 26, no. 1, pp. 53-66.

Leckie, G. (1996) 'Desperately seeking citations: uncovering faculty assumptions about the undergraduate research process', Journal of Academic Librarianship, vol. 22, no. 3, pp. 201-208.

Lee, K. K. (2013) 'The research paper project in the undergraduate writing course', in The New Digital Scholar: Exploring and Enriching the Research and Writing Practices of NextGen Students, eds. R. McClure \& J. Purdy, ASIST, Medford, NJ, pp. 41-63. 


\section{A. Hicks and C. Sinkinson}

Littlejohn, A. (2011) 'Charting' [online] Available at: http://littlebylittlejohn.com/charting/

Lloyd, A. (2007) 'Recasting information literacy as socio-cultural practice: implications for library and information science researchers', Information Research, vol. 12, no. 4, [online] Available at: http://www.informationr.net/ir/12-4/colis/colis34.html

Lloyd, A. (2010) Information Literacy Landscapes: Information Literacy in Education, Workplace and Everyday Contexts, Chandos Publishing, Oxford, UK.

Luke, A. \& Kapitzke, C. (1999) 'Literacies and libraries: archives and cybraries', Pedagogy, Culture and Society, vol. 7, no. 3, pp. 467-491.

Mott, J. (2010) 'Envisioning the post-LMS era: the open learning network', EDUCAUSE Quarterly, vol. 33, [online] Available at: http://www.educause.edu/ero/article/envisioningpost-lms-era-open-learning-network

Mott, J. \& Wiley, D. (2013) 'Open for learning: the CMS and the open learning network', In Education, vol. 15, no. 2, [online] Available at: http://ineducation.couros.ca/index.php/ ineducation/article/view/53

McLoughlin, C. \& Lee, M. (2008) 'The three P's of pedagogy for the networked society: personalization, participation, and productivity', International Journal of Teaching and Learning in Higher Education, vol. 20, no. 1, pp. 10-27.

Nelson, J. (1990) 'This was an easy assignment': examining how students interpret academic writing tasks', Research in the Teaching of English, vol. 24, no. 4, pp. 362-396.

Nelson, J. (1994) 'The research paper: a 'rhetoric of doing' or a 'rhetoric of the finished word?", Composition Studies/Freshman English News, vol. 22, no. 2, pp. 65-75.

Pawley, C. (2003) 'Information literacy: a contradictory coupling', Library Quarterly, vol. 73, no. 4 , pp. $422-452$.

Schaffert, R. \& Hilzensauer, W. (2008) 'On the way towards personal learning environments: seven crucial aspects', eLearning Papers, [online] Available at: http://www.elearningeuropa. info/files/media/media15971.pdf

Siemens, G. (2005) 'Connectivism: a learning theory for the digital age', International Journal of Instructional Technology and Distance Learning, vol. 2, no. 1, pp. 3-10.

Sinkinson, C. \& Hicks, A. (2013) 'Unraveling the research process: social bookmarking and collaborative learning', in The Plugged-In Professor: Tips and Techniques for Teaching with Social Media, eds. S. Ferris \& H. Wilder, Chandos Publishing, Oxford, UK, pp. 49-60.

Stewart, B. (2013) 'Massiveness + openness = new literacies of participation?', Journal of Online Learning and Teaching, vol. 9, no. 2, pp. 228-238.

Swanson, T. (2004) 'A radical step: implementing a critical information literacy model', Portal: Libraries and the Academy, vol. 4, no. 2, pp. 259-273.

Swanson, T. (2005) 'Applying a critical pedagogical perspective to information literacy standards', Community and Junior College Libraries, vol. 12, no. 4, pp. 65-77.

Talja, S. (1997) 'Constituting 'information' and 'user' as research objects: a theory of knowledge formations as alternative to the information man theory', Information Seeking in Context: Proceedings of an International Conference on Research in Information Needs, Seeking and Use in Different Contexts, Taylor Graham, London, pp. 67-80.

Tuominen, K., Savolainen, R. \& Talja, S. (2005) 'Information literacy as a sociotechnical practice', The Library Quarterly, vol. 75, no. 3, pp. 329-345.

Veletsianos, G. \& Kimmons, R. (2012a) 'Assumptions and challenges of open scholarship', International Review of Research in Open \& Distance Learning, vol. 13, no. 4, [online] Available at: http://www.irrodl.org/index.php/irrodl/article/view/1313

Veletsianos, G. \& Kimmons, R. (2012b) 'Networked participatory scholarship: emergent techno-cultural pressures toward open and digital scholarship in online networks', Computers \& Education, vol. 58, no. 2, pp. 766-774.

Ward, D. (2006) 'Revisioning information literacy for lifelong meaning', Journal of Academic Librarianship, vol. 32, no. 4, pp. 396-402.

Weller, M. (2000) 'Using learning environments as a metaphor for educational change', On the Horizon, vol. 17, no. 3, pp. 181-189.

Weller, M. (2011) The Digital Scholar. The digital scholar: how technology is transforming scholarly practice, London, Bloomsbury. 